\title{
Measurement of Social Support Across Women from Four Ethnic Groups: Evidence of Factorial Invariance
}

\author{
Sabrina T. Wong • David Nordstokke • \\ Steven Gregorich • Eliseo J. Pérez-Stable
}

Published online: 25 February 2010

(C) The Author(s) 2010. This article is published with open access at Springerlink.com

\begin{abstract}
To examine whether a multidimensional social support instrument can be used for comparative research in four diverse ethnic groups of women (African American, Latina, Chinese, non-Latina White). The social support instrument was administered as part of a larger survey to 1,137 women. We tested the reliability and validity of this instrument. A confirmatory factor analytic (CFA) framework was used to test for the invariance of the instrument's psychometric properties across ethnic groups. We used multitrait scaling to eliminate items that did not meet the item-convergence criterion $(r>0.30)$ and where items were non-convergent items in at least three groups. A series of nested CFA models assessed the level of factorial invariance. One thousand seventy-four women completed the survey; Their mean age was 61 years with Chinese and Latinas reporting lower education compared to non-Latino Whites $(p<.001)$. A four-factor model (Tangible, Informational, Financial, Emotional/Companionship) fit within each ethnic group separately, suggested good fit.
\end{abstract}

Intended for: The Gerontologist

S. T. Wong $(\bowtie)$

Culture, Gender, Health Research Unit, School of Nursing, and Center for Health Services and Policy

Research, University of British Columbia, 2211 Wesbrook Mall, T-161, Vancouver, BC V6T-2B5,

Canada

e-mail: sabrina.wong@nursing.ubc.ca

S. T. Wong $\cdot$ S. Gregorich $•$ E. J. Pérez-Stable

Center for Aging in Diverse Communities, University of California, San Francisco, Vancouver, BC,

Canada

D. Nordstokke

Department of Educational Psychology: Measurement, Evaluation, and Research Methodology,

University of British Columbia, Vancouver, BC, Canada

S. Gregorich • E. J. Pérez-Stable

Division of General Internal Medicine, Department of Medicine, University of California,

San Francisco, Vancouver, BC, Canada

S. Gregorich • E. J. Pérez-Stable

Medical Effectiveness Research Center for Diverse Populations, University of California, San Francisco, Vancouver, BC, Canada 
Multi-group CFA supported configural and metric invariance across all ethnic groups. Only partial scalar invariance was supported. This 8 -item instrument is a reliable and valid tool that can be used as a multidimensional measure of social support. It can used to examine social support within one ethnic group and for comparative research across diverse ethnic groups of women.

Keywords African American · Latino · Asian · Chinese - Language · Spanish · Confirmatory factor analysis $\cdot$ Psychometric analysis

\section{Introduction}

Having a social network of valued relationships with others plays a critical role in an individual's health status. Simply having fewer contact with others, such as a married partner, friends and relatives, belonging to a church group, or other informal groups, is associated with higher rates of mortality (Berkman and Syme 1979). Individuals with larger social networks are more likely able to tap into different types of social support such as tangible and emotional support (Seeman and Berkman 1988; Seeman and McEwen 1996).

Although social networks and subsequent availability of social support is important for all individuals, especially women, receiving social support for those who are aged 65 years and older may be particularly important. Women, because of their longer life expectancy, have a greater lifetime risk of functional disability and chronic illnesses. Moreover, as women age, they also experience more social, financial, and cultural constraints (Lee Wha et al. 2008). Older women, make up over $70 \%$ of the elderly poor (Bierman and Clancy 2001) and are more at risk economically because traditional role expectations of women have limited their participation in the workforce and they receive less support from children (Lee Wha et al. 2008). Social support, which refers to processes through which social relationships might promote health and well-being (Cohen et al. 2000) and the degree to which interpersonal relationships serve particular functions (Sherbourne and Stewart 1991) is an essential part of successful aging. Rowe and Kahn (1997) suggest three important dimensions of successful aging: (1) low incidence of disease and disease-related disability, (2) high cognitive and physical functional capacity, and (3) active engagement in life. Indeed the multidimensional nature of social support, which typically includes emotional, tangible, informational, and companionship (Wong et al. 2005), influences all three of these dimensions.

Evidence strongly suggests that social support keeps people healthy and helps speed recovery from illness. The availability of someone to provide help or emotional support may protect individuals from some of the negative consequences of major illness or stressful situations (Sherbourne and Stewart 1991). Moreover, social support has salutary effects on physical health and psychological well-being (Cohen et al. 2000; House et al. 1988; Kaplan et al. 1977; Levitt et al. 1985; Thoits 1985). Greater levels of emotional support, specifically, are associated with more positive patterns of cognitive aging and active social engagement (Seeman et al. 2001), as well as decreased levels of depression (Gurung et al. 2003) and increased physical functioning (Seeman and Chen 2002). Increased social support, particularly emotional support is positively associated with life satisfaction, better well-being, less depression, and higher positive affect (Wong et al. 2007). More social support is also associated with higher levels of both physical and mental functioning (Seeman and Chen 2002). 
Assessment of social support requires appropriate measurement, typically using selfreport instruments. Yet, instruments used to assess these experiences may be of limited use with diverse ethnic immigrant groups if they were not developed nor validated with these groups in mind. Instruments developed to measure constructs important to the general public may not have conceptual equivalence (Flaherty 1987; Guillemin et al. 1993; Herdman et al. 1998; Hui and Triandis 1985; Patrick et al. 1994) (e.g. no adequate reflection of social support constructs important to groups who speak little or no English), operational equivalence (Flaherty et al. 1988; Herdman et al. 1998; Hui and Triandis 1985; Patrick et al. 1994) (e.g. appropriate survey methods including reading level, item format, and instructions), or psychometric equivalence (Flaherty et al. 1988; Gonzalez-Calvo et al. 1997; Herdman et al. 1998; Patrick et al. 1994) (e.g. comparable psychometric properties including reliability and validity). As societies age and also become increasingly diverse, understanding similarities and differences in adequacy of social support across ethnic groups will become increasingly important (Day 1996).

While multiple studies have examined the salutary effects of social support in diverse ethnoculutral groups, there is no evidence that any social support measure: (1) represents constructs with equivalent meaning across groups or (2) yields scores that can be meaningfully compared across groups (e.g. that observed score differences reflect true score differences). If mean scores are compared across diverse groups, there is a need to first ensure that the instrumentation can provide a valid basis for making these comparisons (Gregorich 2006; Meredith 1993; Milsap 1998; Yoo 2002). Existing social support measures are potentially limited because they might not adequately reflect the issues and concerns of minority or vulnerable populations and they might not have similar psychometric properties across comparison groups (Stewart and Napoles-Springer 2003). Measurement studies can help determine whether the same dimensions, or latent constructs, are being measured across groups and whether observed score differences reflect 'true' score differences (Stewart and Napoles-Springer 2003). The purpose of this study was to examine if a multidimensional, self-report social support instrument originally developed in older Chinese and Koreans (Wong et al. 2005, 2007) can be used for meaningful comparisons across four diverse ethnic groups (African American, Latino, Chinese, and Non-Latino White) of women.

\section{Methods}

Conceptual framework Based on the conceptual framework of stress and coping (DunkelSchetter et al. 1987), social support is typically defined in terms of various functional domains and refers to any process through which social relationships might promote health and well-being (Cohen et al. 2000). The types of social support dimensions were derived from past empirical work (Broadhead et al. 1988; Krause 2002; Sherbourne and Stewart 1991) and focus group data (Wong et al. 2005). The initial development and testing of this instrument is described in detail elsewhere (Wong et al. 2005, 2007).

Functional support refers to the degree to which interpersonal relationships serve particular functions (Sherbourne and Stewart 1991). The functions most often cited are: emotional, instrumental aid or tangible, information/advice, companionship, and validation (Cohen et al. 2000). Tangible support refers to the provision of assistance with activities of daily living such as transportation, and assistance with cooking, cleaning, and shopping. Financial support refers to assistance through monetary means. While House and Landis (1988) refers to tangible and financial support as instrumental support, in our focus groups 
with older Chinese and Koreans, there was a clear separation between these two domains. Emotional support refers to having a person express sympathy, caring, and acceptance of the individual. Someone who provides information about resources or gives advice is giving the individual informational support. Companionship refers to having a person with whom to share activities such as going to movies, eating together, and shopping. A person who provides validation gives the individual feedback about him/herself.

Nature and sources of survey respondents As part of a larger study, eligible participants included African American, Latino, Asian (mainly Chinese), and non-Latino White women, between 50 years and 80 years of age, fluent in either English and Spanish, or Chinese (Cantonese or Mandarin), and had seen the same clinician for at least one visit in the previous 2 years (Kim et al. 2008). Women were recruited from three clinical sites in San Francisco, screened by telephone, and invited for an extensive face-to-face interview lasting up to $90 \mathrm{~min}$. The clinical sites for recruitment were four primary care practices (two general internal medicine, family medicine, and women's health) at the University of California, San Francisco (UCSF) Medical Center, a community-based clinic in Chinatown, and the Community Health Network Clinics affiliated with the Department of Health and San Francisco General Hospital.

Study procedures The research protocol was approved by the UCSF Committee on Human Research, the Institutional Review Board at San Francisco General Hospital (SFGH), and the Chinatown Clinic Director. We generated a list of potentially eligible women based on available administrative data at each site. Names of patients were submitted to the appropriate clinician listed and permission requested to contact their patients by mail to inform them about the project. Clinicians were asked to return the list with their approval and indicate names of patients not to be contacted (e.g. no longer a patient, cognitively impaired, dead). Personalized letters were mailed to each patient, in English, or English and Spanish or Chinese, informing her about the study and requesting that a postcard be returned by checking a "Not interested, do not call" box or a "Interested, please call me" box. If no postcard was returned within 2 weeks, trained interviewers contacted women to complete a 20-min screening questionnaire in English, Spanish, or Chinese (Cantonese or Mandarin). After 8 months of limited success recruiting Asian women, we began screening and recruiting these women (mostly Chinese) using face-to-face methods at the community-based Chinatown clinic. Our goal was to recruit similar numbers of African American, Asian, Latina, and nonLatino White women and a significant number of limited English proficiency participants.

Women participating in the baseline telephone survey then were asked to participate in a face-to-face survey in the language of their choice. Each face-to-face survey lasted an average of 50-90 min, with the longer survey times occurring for those conducted in Spanish and Chinese. Interviews were conducted at a UCSF research office, a clinical practice site, or their home. Women received $\$ 20$ at the end of the interview in appreciation for their time.

Survey The final survey included items derived from standard questions used in previous surveys and from formative focus groups and individual interviews completed as part of the larger study. The questionnaire was developed simultaneously in English, Spanish, and Chinese using bilingual experts and then pre-tested in each of the four ethnic groups, specifically testing the cultural, linguistic, and literacy appropriateness. Data collected from 
the surveys included socio-demographic characteristics (e.g. age, years of education, household income, language use, birthplace), personal and family history of cancer, use of cancer screening tests, risk perceptions of getting cervical, breast, or colon cancer, health status, social support, and interpersonal processes of care.

Social support instrument The original 27-item social support measure in this survey was first developed for use with older Koreans and Chinese; a review of existing measures revealed no one instrument that captured all domains identified focus groups of older Chinese and Koreans (Wong et al. 2005) or reported psychometric properties in these groups. Responses were a 1-5 likert scale, "none of the time", "a little of time", "some of the time", "most of the time", "all of the time." Items for each subscale were summed and divided by the number of items in the subscale such that each participant had a score for each subscale. This instrument was tested in a sample of older Koreans and Chinese using exploratory factor analytic (EFA) techniques (Wong et al. 2007). The results provided evidence that social support was a reliable and valid multidimensional construct measuring support in the following areas: language (5-items); informational (4-items); financial (4-items); emotional/companionship (8-items).

Tangible support (6-items) is a considered a standard dimension of social support, therefore, we also included this subscale in the current survey and subsequent analyses. For the purposes of this study, we used 22-items that included all the social support dimensions, except for language support because these questions were only answered by people who answered the survey in Spanish or Chinese.

\section{Participants}

We identified and received consent from physicians to send recruitment letters to 4,523 women. We were unable to reach 906 women due to wrong telephone numbers or addresses and 871 were ineligible due to factors such as illness or having left the physician's practice. We were able to contact 2,786 women. Screening data were collected from a total of 1,137 African American $(n=159)$, Latino $(n=236)$, Chinese $(n=353)$, other Asian $(n=63)$, and non-Latino White women $(n=326)$. Other Asian women were excluded due to small sample size. Our sample final size for this study was 1,074 women for women completed the telephone screener and face-to-face interview.

Table 1 displays the socio-demographic characteristics. Women's mean age was 61 years with Latinas being significantly older (63.6 years). Over $80 \%$ of the women had at least one child and over half of all women were married or living with a partner, with Chinese $(73 \%)$ being the most likely to be married or living with someone, and African Americans (30\%) and Latinas (39\%) the least likely to be married or living with a partner. The majority of Chinese and Latinas (68\%, 59\% respectively) reported having significantly less than a high school education compared to non-Latino Whites. Similarly, the many African Americans, Chinese, and Latinas (39\%, 54\%, 50\%, respectively) all reported a significantly lower household income compared to non-Latino Whites. Over one-third of African Americans (31\%) reported being on disability, most Chinese (38\%) were not working, and $34 \%$ of Latinas were retired compared to over one-third of non-Latino whites $(36 \%)$ who were still working full-time. African American, Chinese, and Latinas were significantly less likely to have private insurance and more likely to report being in poor health status $(p<.001)$ compared to non-Latino Whites. Not surprisingly, most Chinese and Latinas were not born in the U.S. 
Table 1 Sociodemographic Characteristics of Women

\begin{tabular}{|c|c|c|c|c|c|}
\hline & $\begin{array}{l}\text { African-American } \\
(n=159)\end{array}$ & $\begin{array}{l}\text { Latino } \\
(n=236)\end{array}$ & $\begin{array}{l}\text { Chinese } \\
(n=353)\end{array}$ & $\begin{array}{l}\text { Non-Latino } \\
\text { White } \\
(n=326)\end{array}$ & $\begin{array}{l}\text { Total } \\
(n=1,074)\end{array}$ \\
\hline Age: Mean (SD) & $60.8(7.8)$ & $63.6(8.8) * * *$ & $60.6(7.2)$ & $60.7(7.5)$ & $61.5(7.9)$ \\
\hline \multicolumn{6}{|l|}{ Parity: n(\%) } \\
\hline No previous children & $18(11)^{* * *}$ & $38(16)^{* * *}$ & $28(8) * * *$ & $127(38)$ & $224(19)$ \\
\hline One child or more & $149(89)$ & $200(84)$ & $325(92)$ & $210(62)$ & $933(81)$ \\
\hline $\begin{array}{l}\text { Married or living with } \\
\text { partner: n }(\%)\end{array}$ & $49(30) * * *$ & $92(39)^{* *}$ & $258(73)^{* * *}$ & $175(52)$ & $610(53)$ \\
\hline \multicolumn{6}{|l|}{ Education: n(\%) } \\
\hline Less than high school & $23(14)^{* * *}$ & $140(59)^{* * *}$ & $242(68)^{* * *}$ & $6(2)$ & $414(36)$ \\
\hline High school graduation & $39(23)$ & $30(12)$ & 48 (14) & $13(4)$ & $137(12)$ \\
\hline Some college or higher & $105(63)$ & $69(29)$ & $63(18)$ & $318(94)$ & $608(52)$ \\
\hline \multicolumn{6}{|l|}{ Income: $\mathbf{n}(\%)$} \\
\hline$\$ 20,000$ or less & $63(39)^{* * *}$ & $116(50)^{* * *}$ & $189(54) * * *$ & $60(18)$ & $437(38)$ \\
\hline$\$ 20,001-\$ 50,000$ & $53(32)$ & 79 (34) & $123(35)$ & $80(24)$ & $357(31)$ \\
\hline More than $\$ 50,000$ & $48(29)$ & $38(16)$ & $40(11)$ & $195(58)$ & $352(31)$ \\
\hline \multicolumn{6}{|l|}{ Employment status: n(\%) } \\
\hline Working full time & $38(24) * * *$ & $29(13) * * *$ & $30(9)^{* * *}$ & $114(36)$ & $229(21)$ \\
\hline Working part time & $10(6)$ & $39(17)$ & $54(15)$ & $46(15)$ & $154(14)$ \\
\hline Not working & $17(11)$ & $33(14)$ & $130(38)$ & $26(8)$ & $212(19)$ \\
\hline Retired & $44(28)$ & $78(34)$ & $100(29)$ & $101(32)$ & $352(32)$ \\
\hline Disability & $49(31)$ & $49(22)$ & $31(9)$ & $28(9)$ & $160(14)$ \\
\hline \multicolumn{6}{|l|}{ Insurance type: $n(\%)$} \\
\hline Private insurance & $85(52)^{* * *}$ & $81(35)^{* * *}$ & $81(24)^{* * *}$ & $252(76)$ & $548(49)$ \\
\hline Public insurance & $68(41)$ & $109(47)$ & $106(31)$ & $70(21)$ & $365(32)$ \\
\hline Uninsured & $11(7)$ & $42(18)$ & $152(45)$ & $11(3)$ & $217(19)$ \\
\hline \multicolumn{6}{|l|}{ Health status: $n(\%)$} \\
\hline Poor & $20(12)^{* * *}$ & $34(14) * * *$ & $83(24) * * *$ & $16(5)$ & $156(13)$ \\
\hline Fair & $59(35)$ & $109(46)$ & $143(41)$ & $45(13)$ & $377(33)$ \\
\hline Good & $57(34)$ & $63(26)$ & $97(27)$ & $103(31)$ & $344(30)$ \\
\hline Very good/excellent & $31(19)$ & 33 (14) & $30(8)$ & $172(51)$ & $281(24)$ \\
\hline \multicolumn{6}{|c|}{ Language survey completed: $n(\%)$} \\
\hline English & $167(100)$ & $58(24)$ & $28(8)$ & 337 (99.7) & $651(56)$ \\
\hline Chinese & $0(0)$ & $0(0)$ & $325(92)$ & $0(0)$ & $327(28)$ \\
\hline Spanish & $0(0)$ & $179(76)$ & $0(0)$ & $1(0.3)$ & $180(16)$ \\
\hline Born in the US: $n(\%)$ & $165(99)^{* *}$ & $24(10)^{* * *}$ & $14(4)^{* * *}$ & $294(87)$ & $510(44)$ \\
\hline
\end{tabular}

Analysis

Using a confirmatory factor analytic (CFA) framework, we sought to test whether the instrument's psychometric properties were invariant across each of the four ethnic groups (African American, Chinese, Latino, and non-Latino White). That is, we assessed whether four common factors (Tangible, Information, Financial, Emotional/Companionship) were 
present among the 22-items of the social support measure within the total sample and within each ethnic group. Four common factors were identified by their specified items (no cross-loadings), common factor variances and co-variances were freely estimated, and all item error variances were constrained to be uncorrelated. None of the models had acceptable fit. Thus a revised empirical model was pursued.

Multitrait scaling was used to examine whether each item within a hypothesized dimension was linearly related ( $r>0.30$, corrected for overlap) to the total score for that dimension (item convergence) and if each item was correlated two or more standard errors higher with its hypothesized domain than with other domains (item discrimination) (Hays and Hayashi 1990; Stewart et al. 1992). We first eliminated items not meeting the item convergence criterion across all in at least three race/ethnic groups. We then eliminated items not meeting the item discrimination criterion using the same approach.

Data from the remaining items were simultaneously modeled with multiple-group CFA. These analyses were used to assess the unidimensionality of items within each originally hypothesized subdomain across the four ethnic groups. Items were dropped via a process of backward elimination, either because they did not have salient loadings $(<0.40)$ on the hypothesized factor, or loaded highly on more than one factor.

Next, we conducted a series of nested models to assess the level of factorial invariance across the four ethnic groups. We assessed configural invariance to examine whether each common factor was associated with identical item sets across the ethnic groups. A multi-group model specified four factors with identical item sets across the four ethnic groups. All parameters were freely estimated. We then examined metric invariance which constrained corresponding factor loadings to be equal across groups. Finally, we assessed strong factorial invariance, also known as scalar invariance, which requires that regression of items onto their associated common factors yields a vector of intercept terms that is invariant across the ethnic groups (Gregorich 2006). That is, the corresponding item intercepts were also held equal across groups in addition to the constraints of metric invariance.

All CFA models were fit using LISREL 8.5 software (Jöreskog and Sörbom 1998). Goodness of fit was assessed by examining model chi-squares and degrees of freedom, the root mean square error of approximation (RMSEA, Steiger 1990), and the comparative fit index (CFI, Bentler 1990). Significant chi-squares and chi-square difference tests indicate lack of exact fit. It is known that the chi-square goodness-of-fit test can too often reject correct models (Type I error) with finite samples of nonnormal data. Therefore the root-mean-square error of approximation (RMSEA), the comparative fit index (CFI), and the expected cross-validation index (ECVI) were also used to assess model fit. Values of RMSEA $<0.05$ and values of $\mathrm{CFI} \geq 0.95$ suggest approximate fit (Browne and Cudeck 1993; Hu and Bentler 1999). In a series of nested models, the ECVI will obtain relatively lower values for models with higher expectation of replication in subsequent samples of the same size. Ninety percent confidence intervals were included to supplement the point estimates of RMSEA and ECVI (Browne and Cudeck 1993). Selection of cross-group equality constraints to relax was based on LISRL's 8.5 modification indices.

Missing data $(<5 \%$ of data points) were dealt with using the linear interpolation algorithm of SPSS version 16.0 (SPSS Inc, 2008) which uses nearby data points to estimate missing values. The skew and kurtosis of each item were investigated to assess normality of the distributions. Provided that each social support dimension met the criteria for configural, metric, and scalar invariance, we then compared the means using the appropriate statistical test, analysis of variance with post-hoc comparisons. 


\section{Results}

Fourteen items were eliminated; Seven items were eliminated through the process of multitrait scaling and another seven items were dropped through the process of backward elimination (see Table 2), leaving a total of eight items. The modified measurement model consisted eight items representing four first-order common factors: Information, Financial, Emotional/Companionship, and Tangible support (see Table 3). Although the data are not shown, skewness values ranged from -0.71 to 0.51 and kurtosis values ranged from -1.32 to -0.13 indicating that distributions were roughly symmetrically distributed (Tabachnick and Fidell 2001). Prior to testing factorial invariance, the four factor model was fit within each ethnic group, separately. All models suggested good fit: Chi-square tests were all nonsignificant (Table 4).

Table 5 displays the results for construct validity; That is, the confirmatory factor analyses and our assessment of invariance between the ethnic groups. Confirgural invariance, each factor (e.g. tangible support, financial support) is associated with the same set of items across the different ethnic groups. The first multi-group CFA model tested for configural invariance between the four ethnic groups. This model had acceptable model fit with a non-significant $\chi^{2}=57.02, p=0.44$, suggesting configural invariance across all four groups. Model 2 also supported metric invariance, $\chi^{2}=69.28, p=0.43$.

Full scalar invariance was not supported meaning that the corresponding factor loads for each item in each item set is not the same across ethnic groups. However, when we relax the equality constraint for some of the items, we were able to achieve partial scalar invariance. The model chi-square test was significant, $\chi^{2}=146.88 \quad(p=0.0001)$, and compared to Model 2, significant increases were noted in the RMSEA and ECVI values. Therefore, Model 4 tested partial scalar invariance. Based upon modification indices, the equality constraint on the intercept for item, "Helps with chores" in the Latino group was relaxed. The intercept for the Latino group was slightly higher than the other groups at -0.11 , whereas the intercepts for the other three ethnic groups were -0.52 . With that constraint removed the model chi-square remained significant, $\chi^{2}=121.63, p=0.0015$, and the RMSEA and ECVI point estimates were outside the corresponding confidence intervals estimated for Model 2, which arguably had the best model fit. Therefore, a further modification was sought. In Model 5 the equality constraint on the intercept estimate of, "Pays for expenses on a regular basis" for the Chinese group was removed. The intercept for the Chinese group was slightly higher at -0.15 than the other ethnic groups whose intercepts were -0.48 . Model 5 resulted in a non-significant $\chi^{2}=95.74, p=0.084$, and was selected as the 'best' empirically modified model with respect to model fit and parsimony.

Table 6 shows the internal consistency reliability (cronbach's alpha) and mean scores for each of the final four social support domains (Tangible, Informational, Financial, Emotional/Companionship) for each of the four ethnic groups. The cronbach's alphas were: Tangible: 0.85, Informational: 0.90, Financial: 0.91, and Emotional/Companionship: 0.82 . The scale scores used in the mean comparisons, across the four ethnic groups, were compiled from the items used to achieve scalar invariance thus the scale score for Tangible support for the Latino group includes only the item, "Help get things done in house", and the scale score for Financial support in the Chinese group includes only the item, "Give money now and then." For Tangible, Informational, Financial, and Social/emotional support the Chinese groups scored significantly lower than the other three ethnic groups $(p<0.01)$. Non-Latino Whites and African Americans were not significantly different across any of the social support dimensions. Thus, for any mean comparisons between non-Latino Whites and African Americans, all eight items can be used. Any mean comparison of 
Table 2 Social Support Items "How Much of the Time Can You Count On Someone To... Responses Were: "None of the Time", "A Little of Time", "Some of the Time", "Most of the Time", "All of the Time"

Original 22 items use in mulittrait scaling analysis
15 items retained after multitrait scaling: Items used in multiple-group confirmatory items factor analysis
Tangible support

Help you get things done in the house such as chores (e.g. washing dishes, vacuuming)

Help you with taking care of any paperwork (e.g. bills, jury duty)

Help you prepare meals or cook for you

Help you with shopping or other errands such as doing laundry

Help carry heavy things such as groceries

Provide you with some transportation

Go with you to appointments

(e.g. doctor's appointment)

Informational support

Give you information to help you understand a situation (e.g. where to apply for SSI, how to get a passport, how to file an income tax return)

Suggest who you could see for assistance with a problem that you were having

Give you suggestions about how to deal with a personal problem (e.g. stress with work and family)

Give you useful advice about important things in life (e.g. dealing with family conflicts)

Financial support

Give you money now and then, if you needed it

Pay for expenses (e.g. rent, telephone bill) on a regular basis, if you needed it

Buy food or something else so you don't have to spend your money

Give you pocket money

Emotional/companionship

Love you and make you feel wanted

Listen to you when you need to talk

Confide in or talk to about yourself or you problems
Help you get things done

Help with paperwork (e.g. bills, jury duty)

Help prepare meals or cook

Help you with shopping or other errands such as doing laundry

Help carry heavy things such as groceries

Give you information

Suggest who you could see for assistance

Give you money now and then, if you needed it

Pay for expenses if needed

Buy food or something else so you don't have to spend your money

Give you pocket money

Love you and make you feel wanted Listen to you when you need to talk Confide in or talk to
Give you information

Help you get things done

Help with paperwork (e.g. bills, jury duty)

Help prepare meals or cook

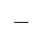

\section{Suggest who you could see for} assistance

$-$

Give you money now and then, if you needed it

Pay for expenses if needed

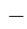

$-$

Confide in or talk to 
Table 2 (continued)

\begin{tabular}{lll}
\hline $\begin{array}{l}\text { Original } 22 \text { items use in mulittrait } \\
\text { scaling analysis }\end{array}$ & $\begin{array}{l}15 \text { items retained after multitrait scaling: } \\
\text { Items used in multiple-group confirmatory } \\
\text { factor analysis }\end{array}$ & $\begin{array}{l}\text { Final } 8 \text { social support } \\
\text { items }\end{array}$ \\
\hline $\begin{array}{l}\text { Help you feel better when you are } \\
\text { sad or lonely }\end{array}$ & - & - \\
Get together for relaxation & Get together for relaxation & $\begin{array}{c}\text { Get together for } \\
\text { relaxation }\end{array}$ \\
Go out and do things with & - & - \\
Eats meals together & - & - \\
\hline
\end{tabular}

tangible support across Latinos and other ethnic groups should only use the one item. However, when examining tangible support within Latinos, then all items can be used. Similarly, any comparison of financial support involving Chinese and other ethnic groups should only use the one item. Yet, when examining financial support within Chinese, all items can be used.

\section{Discussion}

This study is unique in its contribution of a valid and reliable, 8-item social support instrument available in English, Spanish, and Chinese. Using the CFA framework, we were able to test whether the subscales (and items within each subscale) indirectly measured the latent construct of social support. Moreover, these results provide evidence of construct

Table 3 Final Social Support Items from Partial Scalar Invariance Model (Model 5-Standardized Solution)

\begin{tabular}{lcc}
\hline Type of support and items & Factor loading & Intercept \\
\hline Tangible support & 0.82 & 0 \\
Help get chores done in house & 0.89 & -0.53 \\
Helps with paper work & & $0.11^{*}$ \\
& & 0.89 \\
Informational support & 0.87 & 0.12 \\
Information to understand a situation & & 0 \\
Give assistance about a problem you were having & 0.90 & -0.05 \\
Financial support & & $-0.15^{* *}$ \\
Give money now and then & 0.90 & 0 \\
Pay for expenses on a regular basis & & 0.035 \\
Emotional/companionship support & 0.85 & 0.76 \\
Confide in or talk about problems & & 0.12 \\
Get together for relaxation &
\end{tabular}

For the items, "Helps with paper work" and "Give money now and then" that did not meet scalar invariance, two intercept estimates are shown

${ }^{\text {a }}$ Intercept for Latino group

${ }^{\mathrm{b}}$ Intercept for Chinese group on item 
Table 4 Confirmatory Factor Analysis of Social Support By Ethnic Group

\begin{tabular}{lcccc}
\hline Ethnic group & $\mathrm{N}$ & $\chi^{2}$ & $\mathrm{p}$ & RMSEA \\
\hline African-American & 159 & 10.1 & 0.75 & 0.00 \\
Latino & 236 & 7.55 & 0.91 & 0.00 \\
Chinese & 353 & 20.51 & 0.11 & 0.04 \\
Non-Latino White & 326 & 18.86 & 0.17 & 0.03 \\
\hline
\end{tabular}

validity across four ethnic groups and that mean comparisons of the subscale scores would reflect true group differences that are not contaminated by group-specific attributes.

Researchers have been called to demonstrate that the additional methodological rigor of developing measures used for comparative research produces superior results (Stewart and Napoles-Springer 2003). Although previous work has shown that less financial support is associated with more anxiety (Wong et al. 2007), the added value of this study is also new theoretical insight into the multidimensional construct of social support. For women, obtaining financial support is a distinctly different from obtaining tangible support. This dimension of social support may be particularly salient to older women, who tend to live longer than men and may have less financial security. Indeed minority elderly men and women (those aged 65 years and older), as well as non-Latino white women are more likely to earn lower median incomes compared to White men (Estes 2001). Moreover, White women tend to have incomes at least $50 \%$ greater than those earned by both African American and Latino women (Estes 2001).

The factor structure of this instrument suggests that there are conceptual similarities in constructs being measured in English, Spanish, and Chinese. Our evidence of metric invariance suggests that all eight items identified four factors with identical meanings across all four ethnic groups. Thus, this instrument can be used to examine the relationship between different types of social support and health processes and outcomes either within one ethnic group (e.g. Chinese) or for comparative research across non-Latino White, African American, Chinese, and Latino women. Using this measure can also give clinicians a tool to assess multiple dimensions (tangible, socio-emotional, financial, and information) of social support. The evidence for partial scalar invariance suggested that group differences in observed means are not contaminated by differential additive response bias (Gregorich 2006). That is, the evidence suggests that group mean comparisons reflect true group differences on the measured constructs.

Table 5 Confirmatory Factor Analyses, Configural, Metric, and Scalar Invariance, for Final Social Support Items $(n=8)$

\begin{tabular}{lccccc}
\hline Model & $\chi^{2}$ & df & RMSEA (90\% CI) & ECVI (90\% CI) & CFI \\
\hline 1. Configural invariance model & $57.02(p=0.44)$ & 56 & $0.008(0.00-0.04)$ & $0.27(0.26-0.28)$ & 1.00 \\
2. Metric invariance model & $69.28(p=0.43)$ & 68 & $0.008(0.00-0.04)$ & $0.26(0.23-0.27)$ & 1.00 \\
3. Scalar invariance model & $146.88^{\mathrm{a}}(p=0.0001)$ & 80 & $0.056(0.04-0.07)$ & $0.32(0.26-0.32)$ & 0.99 \\
4. Partial scalar model 1 & $121.63^{\mathrm{a}}(p=0.0015)$ & 79 & $0.045(0.02-0.07)$ & $0.29(0.24-0.38)$ & 0.99 \\
5. Partial scalar model 2 & $95.74(p=0.08)$ & 78 & $0.029(0.00-0.05)$ & $0.27(0.23-0.27)$ & 1.00 \\
\hline
\end{tabular}

${ }^{\mathrm{a}}$ Indicates a significant $\chi^{2}$ 
Table 6 Comparison of Social Support Means Across Ethnic Groups

\begin{tabular}{llllll}
\hline $\begin{array}{l}\text { Type of } \\
\text { support }\end{array}$ & $\begin{array}{l}\text { African American, } \\
\text { mean(SD) }\end{array}$ & $\begin{array}{l}\text { Latino, } \\
\text { mean(SD) }\end{array}$ & $\begin{array}{l}\text { Chinese, } \\
\text { mean(SD) }\end{array}$ & $\begin{array}{l}\text { Non-Latino White, } \\
\text { mean(SD) }\end{array}$ & $\begin{array}{l}\text { Internal consistency } \\
\text { reliability, } \\
\text { Cronbach's } \alpha\end{array}$ \\
\hline Tangible & $3.49(1.17)$ & $2.98(1.38)^{*}$ & $2.63(1.29)^{*}$ & $3.87(1.22)$ & 0.85 \\
Informational & $3.81(1.06)$ & $3.12(1.27)^{*}$ & $2.38(1.01)^{*}$ & $3.72(1.15)$ & 0.90 \\
$\begin{array}{l}\text { Financial } \\
\text { Emotional/ } \\
\text { companionship }\end{array}$ & $3.21(1.31)$ & $2.65(1.38)^{*}$ & $2.00(1.12)^{*}$ & $3.33(1.37)$ & 0.91 \\
\hline
\end{tabular}

Significantly different from three other groups, $p<0.01$

Scalar invariance allows for defensible group comparisons of the observed means, instruments that do not meet these criteria many be counterproductive in comparative research (Gregorich 2006). However, in the case of this social support instrument, dropping the specific items that did not meet scalar invariance allows us to compare subscale means across the different groups. Further work, especially for the tangible and financial support scales, is needed to test additional items for invariance if comparative research is to be conducted with these particular subscales. If the focus analysis is restricted to comparing the strength of corresponding regression parameters across groups, then metric invariance is sufficient if one of the following holds: (1) the regression model corrects for measurement errors in explanatory variables (e.g. a structural equation model with latent variables) or (2) the reliabilities of corresponding explanatory variables are invariant across groups (Gregorich 2006). Therefore, the entire eight item instrument may defensibly be used to compare the strength of the regression parameters across non-Latino White, African American, Chinese, and Latino women.

Despite the unique contributions of this study, these results have some limitations. These results may not be generalizable to men or other samples because data were collected in San Francisco where there are high concentrations of Latino, African American, and Chinese women. However, these data were collected in three languages that included Spanish, Chinese, and English from a large sample of Chinese, Latino, and African American older women. It is important to note, however, that these models were derived from convenience samples in an exploratory manner, and further research attempting to replicate them is required.

In conclusion, this study provides evidence that mean comparisons of different dimensions of social support can be reported across four different ethnic groups in women. While more work is needed to assess the utility of this instrument in men and other ethnic groups, these results provide evidence that this instrument provides reliable and valid measures of social support that can be used to make meaningful comparisons across ethnic groups.

Acknowledgements The authors thank our many research assistants and the men and women who participated in this study. We also acknowledge the support of Dr. Sue Kim in overseeing the collection of data. This study was supported by the Agency for Healthcare Research and Quality (5P01 HS10856) for an Excellence Center to Eliminate Ethnic/Racial Disparities (EXCEED) and by grant (P30-AG15272) under the Resource Centers for Minority Aging Research program by the National Institute on Aging, the National Institute of Nursing Research, and the National Center on Minority Health and Health Disparities, National Institutes of Health. Dr. Wong was supported by a NIA Diversity Supplement (PA-01-079) and a Michael Smith Scholar Award (CI-SCH-051). 
Open Access This article is distributed under the terms of the Creative Commons Attribution Noncommercial License which permits any noncommercial use, distribution, and reproduction in any medium, provided the original author(s) and source are credited.

\section{References}

Bentler, P. M. (1990). 'Comparative fit indexes in structural models. Psychological Bulletin, 107(2), 238-246.

Berkman, L., \& Syme, C. (1979). Social network, host resistance, and mortality: a nine-year follow-up study of Alameda County residents. American Journal of Epidemiology, 109, 196-204.

Bierman, A., \& Clancy, C. (2001). Health disparities among older women: identifying opportunities to improve quality of care and optimize functional health outcomes. Journal of Americal Medical Womens Association, 56, 155-160.

Broadhead, W., Gehlbach, S., DeGruy, F., \& Kaplan, B. (1988). The Duke-UNC functional social support questionnaire. Measurement of social support in family medicine patients. Medical Care, 26, 709-723.

Browne, M. W., \& Cudeck, R. (1993). Alternative ways of assessing model fit. In K. A. Bollen \& S. Long (Eds.), Testing structural equation models (pp. 136-162). Newbury Park: Sage.

Cohen, S., Gottlieb, B., \& Underwood, L. (2000). Social relationships and health. In S. Cohen, L. Underwood, \& B. Gottlieb (Eds.), Social support measurement and intervention (pp. 3-28). New York: Oxford University Press.

Day, J. (1996). Population projects of the United States by age, sex, race, and Hispanic origin: 1995-2050. Washington: Bureau of the Census.

Dunkel-Schetter, C., Folkman, S., \& Lazarus, R. S. (1987). Correlates of social support receipt. Journal of Personality and Social Psychology, 53, 71-80.

Estes, C. (2001). Sex and gender in the political economy of aging. In C. Estes \& Associates (Eds.), Social policy \& aging: A critical perspective (pp. 119-135). Thousand Oaks: Sage.

Flaherty, J. (1987). Appropriate and inappropriate research methodologies for Hispanic mental health. In M. Gaviria \& J. Arana (Eds.), Health and behavior: Research agenda for Hispanics (pp. 177-186). Chicago: University of Illinois.

Flaherty, J., Gaviria, M., Pathak, D., Mitchell, T., Wintrob, R., Richman, J., et al. (1988). Developing instruments for cross-cultural psychiatric research. Journal of Nervous and Mental Disorders, 176, 257263.

Gonzalez-Calvo, J., Gonzalez, V., \& Lorig, K. (1997). Cultural diversity issues in the development of valid and reliable measures of health status. Arthritis Care Research, 19, 448-456.

Gregorich, S. E. (2006). Do self-report instruments allow meaningful comparisons across diverse population groups? testing measurement invariance using the confirmatory factor analysis framework. Medical Care, 44, S78-S94.

Guillemin, F., Bombardier, C., \& Beaton, D. (1993). Cross-cultural adaptation of health-related quality of life measures: literature review and proposed guidelines. Journal of Clinical Epidemiology, 46, 14171432.

Gurung, R., Taylor, S., \& Seeman, T. (2003). Accounting for changes in social support among married older adults: insights from the MacArthur studies of successful aging. Psychology and Aging, 18(3), 487-496.

Herdman, M., Fox-Rushby, J., \& Badia, X. (1998). A model of equivalence in the cultural adaptation of HRQoL instruments: the universalist approach. Quality of Life Research, 7(4), 323-335.

House, J. \& Landis, K. (1988). 'Structures and processes of social support', Annual Review of Sociology, vol. 14, pp. 293_318.

House, J., Landis, K., \& Umberson, D. (1988). Social relationships and health. Science, 241, 540-545.

Hu, L.-T., Bentler, P. M. (1999). Cutoff criteria for fit Indexes in covariance structure analysis: Conventional criteria versus new alternatives. Structural Equation Modeling, 6, 1-55.

Hui, C., \& Triandis, H. (1985). Measurement in cross-cultural psychology: a review and comparison of strategies. Journal of Cross-Cultural Psychology, 16, 65-83.

Jöreskog, K. G., and D. Sörbom. 1998. New Statistical Features in Lisrel 8.30. Chicago: Scientific Software.

Kaplan, B. H., Cassel, J. C., \& Gore, S. (1977). Social support and health. Medical Care, 15, 47-58.

Kim, S.E., Pérez-Stable, E.J. \& Wong, S.T., Gregorich, S, Sawaya, G.F., Walsh, J., \& Kaplan, C.P. (2008) Effects of Cancer Risk Perception on Screening Behavior Among Diverse Women. Archives of Internal Medicine, 168(7), 728-734

Krause, N. (2002). Church-based social support and health in old age; exploring variations by race. Journal of Gerontology B. Psychological Sciences and Social Sciences, 57(6), S332-S347. 
Lee Wha, T., Kim, S., \& Young Joe, S. (2008). Changing healthcare issues and context for elderly women in Asia: implications for a research agenda for nursing. Nursing Outlook, 56(6), 303-313.

Levitt, M., Antonucci, T., Clark, M., Rotton, J., \& Finley, G. (1985). Social support and well-being: preliminary indicators based on two samples of the elderly. International Journal of Aging and Human Development, 21(1), 61-77.

Meredith, W. (1993). Measurement invariance, factor analysis and factorial invariance. Psychometrika, 58, $525-543$.

Milsap, R. E. (1998). Group differences in regression intercepts: implications for factorial invariance. Multivariate Behavioral Research, 33, 403-424.

Patrick, D., Wild, D., Johnson, E., Wagner, T., \& Martin, M. (1994). Cross-cultural validation of quality of life measures. Paper presented at the Quality of Life Assessment: International Perspectives, Berlin, Germany.

Rowe, J.W. \& Kahn, R.W., (1997) Successful aging, Gerontologist, 38(2), 151.

Seeman, T., \& Berkman, L. (1988). Structural characteristics of social networks and their relationship with social support in the elderly: who provides support. Social Science and Medicine, 26(7), 737-749.

Seeman, T., \& McEwen, B. (1996). Social environment characteristics and neuroendocrine functions: the impact of social ties and support on neuroendocrine regulation. Psychosomatic Medicine, 58, 459-471.

Seeman, T., \& Chen, X. (2002). Risk and protective factors for physical functioning in older adults with and without chronic conditions: MacArthur studies of successful aging. Journal of Gerontology: Social Sciences, 57(3), S135-S144.

Seeman, T., Lusignolo, T., Albert, M., \& Berkman, L. (2001). Social relationships, social support, and patterns of cognitive aging in health, high-functioning older adults: MacArther studies of successful aging. Health Psychology, 20(4), 243-255.

Sherbourne, C., \& Stewart, A. (1991). The MOS social support survey. Social Science and Medicine, 32(6), $705-714$.

Steiger, J. H. (1990). Structural model evaluation and modification: An interval estimation approach. Multivariate Behavioral Research, 25, 173-180.

Stewart, A. L., \& Napoles-Springer, A. M. (2003). Advancing health disparities research: can we afford to ignore measurement issues? Medical Care, 41(11), 1207-1220.

Tabachnick, B., \& Fidell, L. (2001). Using multivariate statistics (4th ed.). Toronto: Allyn and Bacon.

Thoits, P. A. (1985). Social support and psychological well-being: Theoretical possibilities. Dordrecht: Mijhoff.

Wong, S., Yoo, G., \& Stewart, A. (2005). Examining types of social support and actual sources of support in older Chinese and Korean immigrants. International Journal of Health and Human Development, 61(2), $105-121$.

Wong, S., Yoo, G., \& Stewart, A. (2007). An empirical evaluation of social support and psychological wellbeing in older Chinese and Korean immigrants. Ethnicity and Health, 12(1), 43-67.

Yoo, B. (2002). Cross-group comparisons: a cautionary note. Psychology and Marketing, 19, 357-368. 